\title{
A EDUCAÇÃO CTS E OS PROCESSOS DE FORMAÇÃO E ATUAÇÃO DOCENTE EM CIÊNCIAS: UMA REVISÃO BIBLIOGRÁFICA
}

\section{The Education in Science Technology and Society and the Process of Formation and Teaching Science: A Review of the Literature}

Daiane Kist ${ }^{1}$

Sinara München ${ }^{2}$

Resumo: Este artigo teve como foco identificar e analisar pesquisas sobre a formação e as práticas docentes de professores de Ciências e a Educação Ciência, Tecnologia e Sociedade (CTS). A abordagem metodológica é qualitativa, sendo um trabalho de revisão bibliográfica composto pela investigação de dissertações e teses da Biblioteca Digital de Teses e Dissertações (BDTD) do IBICT (Instituto Brasileiro de Informação em Ciência e Tecnologias), iniciando-se com uma busca temática das palavras-chave "formação de professores", "CTS" e "prática". Os trabalhos foram analisados de acordo com a Análise Textual Discursiva, com duas categorias estabelecidas, a priori, denominadas: (1) Possibilidades e desafios da abordagem CTS no processo de formação continuada; (2) Desenvolvimento das práticas docentes com orientação CTS na Educação Básica. Os resultados encontrados contribuem com a ideia de inserção de diversas possibilidades para o processo de formação continuada e nos direcionam para o desenvolvimento de novas práticas pedagógicas na educação básica, com o intuito de inter-relacioná-las com o enfoque CTS. A falta de formação docente sobre CTS é um dos destaques dos trabalhos de pesquisa, o que implica diretamente nos discursos, compreensões e ações, a qual limita a prática docente voltada para esse enfoque.

Palavras-chave: Prática docente. Formação continuada. CTS.

Abstract: The focus of this article was to identify and to analyze researches about teacher's
practice and teacher' formation from teachers of Science and the Science Technology and
Society (CTS) Education. The methodological approach is qualitative, that comprises a
research and bibliographic review of dissertations and theses from the Brazilian Digital
Library of Theses and Dissertations (BDTD) and the Brazilian Institute of Information in
Science and Technology (IBICT), starting at the thematic search of the key-words: teachers'
formation, CTS and practice. The papers were analyzed according to the Discourse Textual
Analysis with two categories established, beforehand, called: 1) Possibilities and challenges
of CTS approach in the process of continuing education; 2) Development of teaching
practices with the orientation CTS on basic education. The results contribute to the idea of
inserting many possibilities for the process of continuing education and directing us to the
development of new pedagogical practices of basic education, with the intention of

1 Especialista em Metodologia do Ensino de Biologia e Química e Mestranda em Ensino de Ciências. Universidade Federal da Fronteira Sul (UFFS). ORCID. https://orcid.org/0000-0002-6475-3568. E-mail: dayanekist@gmail.com.

2 Doutora em Educação em Ciências. Docente na Universidade Federal da Fronteira Sul (UFFS). ORCID: https://orcid.org/0000-0001-6163-9308. E-mail: sinara.munchen@uffs.edu.br 
interrelating them with the focus of CTS. Lack of teachers' training on CTS is one of the prominences of the research work, which implies directly in discourses, comprehensions and actions, which limits the teaching practice oriented to this focus.

Keywords: Teaching practice. Continuing formation. STS.

\section{Introdução}

O presente trabalho teve como foco identificar e analisar as pesquisas que investigam a formação e as práticas docentes de professores de Ciências em articulação com a Educação Ciência, Tecnologia e Sociedade (CTS). Tal abordagem é considerada relevante por manifestar que precisamos formar cidadãos críticos e conscientes, perante as modificações científico-tecnológicas que permeiam nossa sociedade, de acordo com Santos e Schnetzler (2010), “o Ensino de Ciências está vinculado à Educação científica do cidadão". A formação de sujeitos críticos e participativos na Educação Básica está vinculada à capacidade de transformação do mundo em que vivemos, a partir de uma compreensão ampliada de problemáticas científico-tecnológicas.

Da mesma forma, os autores em questão ressaltam que a diferença entre o ensino tradicional e o ensino com enfoque CTS encontra-se na organização por temas sociais e na concepção de ciência, voltada para o interesse social que sempre busca compreensões sobre as implicações sociais do conhecimento científico (SANTOS; SCHNETZLER, 2010). Por fim, a educação com enfoque CTS defende a formação de cidadãos pensantes e capazes de atuar e modificar o meio em que vivem.

O ensino e a aprendizagem ancorados ao enfoque CTS são dependentes das compreensões do professor sobre os pressupostos desse enfoque. Auler e Delizoicov (2006, p. 338) relatam que "[...] compreensões de professores sobre interações entre Ciência-Tecnologia-Sociedade (CTS) têm sido apontadas como um dos pontos de estrangulamento, emperrando, muitas vezes, a contemplação do enfoque CTS no processo educacional".

Para que seja possível realizar um trabalho educacional voltado para o enfoque CTS, é necessário um debate sobre o currículo. Para Auler (2011), existem currículos de Física e Química que permanecem intocáveis por décadas, fato que indica a necessidade de sérias mudanças teórico-metodológicas na Educação Básica, caso contrário, a ideia de inserção de discussões no campo de trabalho CTS poderá transformar-se em mais um modismo educacional.

Abordar os conceitos importantes das Ciências, a partir da educação CTS, é uma tarefa que exige algumas modificações, uma delas está na prática docente do professor, que encara o desafio de repensar o seu fazer docente a partir do enfoque CTS. Penha e Maciel (2019, p. 152) afirmam que "nós, professores, bem o sabemos que não é assim, tão simples, ir ao armário e retirar o conhecimento que precisamos usar em determinada situação de ensino".

Ao pensarmos em modificação da prática docente, evidenciamos as ideias de Strieder e Kawamura (2017), quando as autoras descrevem que, ao abordar a educação CTS, o foco de trabalho passa a ser nas situações-problema que fazem parte do cotidiano dos alunos para que entendam o mundo que os cerca. Dessa forma, nos remetemos a pensar que a abordagem por temas tem como objetivo envolver o cotidiano dos estudantes.

A abordagem por temas relaciona-se com o ato de partir de uma problemática geral e afunilar este debate até chegar ao ponto de explicitar os conceitos científicos. Strieder e 
Kawamura (2017) descrevem algumas abordagens temáticas, uma delas relaciona-se com o estudo sobre a construção e montagem de uma usina nuclear, partindo, inicialmente, dos impactos ambientais provocados por essa ação e, posteriormente, afunila as discussões até chegar aos conceitos científicos relacionados.

Ao falar em modificação da prática docente, pode-se pensar na formação inicial dos professores, que seria responsável pelos seus importantes aspectos formativos, pois acredita-se que o professor ensina aquilo que aprende e vivencia. Nesse sentido, é preciso inserir na formação inicial elementos referentes à abordagem CTS, para que isso possa ser rediscutido, posteriormente, em formações continuadas, a partir dos desafios da sala de aula, visto que sem um conhecimento prévio essas propostas não são colocadas em prática (MÜNCHEN, 2016).

A Educação Básica conta com a atuação de professores formados em diversos modelos e propostas de cursos de formação inicial, quando os parâmetros e as legislações de formação eram diferentes das atuais. Cabe-nos pensar na formação continuada como mecanismo de transformação e ressignificação das práticas dos professores, para, assim, ter a possibilidade de inserir, nesses programas, abordagens calcadas nos princípios da Educação CTS.

Tanto a formação inicial quanto a continuada refletem na prática docente dos professores, pois estes só serão capazes de trabalhar calcados no enfoque CTS se tiveram algum contato com essa abordagem durante a sua formação, assim como afirmam Santos e Schnetzler (2010, p. 96): "sabe-se que o professor é a figura-chave na determinação do sucesso e do fracasso de uma nova abordagem de ensino".

Santos e Schnetzler (2010) reforçam que os professores são os precursores para a adoção de qualquer proposta de ensino, são responsáveis pela prática docente, e a formação deve desenvolver no professor atitudes de investigação das concepções dos estudantes e, como consequência, será formado o professor pesquisador, que precisa

[...] da existência de uma formação continuada enquanto estiver atuando em sala de aula. Tal formação deveria englobar conhecimentos que vão desde os conteúdos mais específicos relacionado às questões das interações entre ciência, tecnologia $\mathrm{e}$ sociedade, até os princípios metodológicos, incluindo aí uma concepção de ensino-aprendizagem construtivista (SANTOS; SCHNETZLER, 2010, p. 130).

Através da formação continuada deve ser possível a qualificação da formação dos professores, pois esses precisam embasar as modificações necessárias na prática docente com o intuito de pensar o ensino de ciências contextualizado, aspecto que também é evidenciado na educação CTS. Ao apresentar as relações anteriormente apontadas, este trabalho tem como foco identificar e analisar produções referentes a formação e atuação de professores de ciências e as inter-relações com a educação CTS.

\section{Metodologia}

Com intuito de compor a pesquisa, foram analisadas dissertações e teses que abordam aspectos relacionados à formação continuada, prática docente e educação CTS. Este é um estudo de caráter qualitativo, do tipo bibliográfico, o qual é caracterizado por Lüdke e André (2013) como pertinente e importante, uma vez que pode indicar os questionamentos mais relevantes na literatura sobre o objeto pesquisado. 
A pesquisa da temática foi realizada na Biblioteca Digital de Teses e Dissertações (BDTD) do IBICT (Instituto Brasileiro de Informação em Ciência e Tecnologias). A BDTD é um espaço de busca, onde são disponibilizadas teses e dissertações defendidas em todas as instituições de ensino e pesquisa do país. A busca realizou-se, especificamente, através do arquivamento dos trabalhos, nos dias 28 e 29 de abril, do ano de 2020.

A busca avançada foi realizada utilizando-se das palavras-chave "CTS", "formação de professores" e "prática", a partir das quais foram encontrados 88 trabalhos, que se dividem em 67 dissertações e 21 teses. Cabe ressaltar que não estipulamos um período definido para a busca, coletando todos os resultados disponíveis na BDTD que contemplassem os termos de busca, resultando em pesquisas compreendidas entre os anos de 2005 e 2019.

Com o quadro inicial composto pelas 88 teses e dissertações, foi feita a seleção daquelas que estavam alinhadas com a atuação docente de professores de Ciências na Educação Básica e a formação continuada de Professores, associadas às práticas educativas com enfoque CTS. Essa etapa ocorreu com a leitura do título, palavras-chave e resumos das dissertações e teses, resultando, ao final, em 11 pesquisas selecionadas.

As teses e dissertações não selecionadas se distanciavam do tema em questão por tratarem, majoritariamente, da formação inicial de professores, das compreensões de alunos da educação básica, assim como algumas se voltavam para a educação técnica e tecnológica, ou estavam ligadas diretamente a outras áreas que envolvem CTS. Das 11 dissertações e teses que se aproximam especificamente da temática de pesquisa, nove são dissertações e duas são teses.

A análise das teses e dissertações foi realizada utilizando-se da dinâmica da Análise Textual Discursiva (ATD) (MORAES; GALIAZZI, 2016), que corresponde a uma metodologia de análise de natureza qualitativa com a finalidade de produzir novas compreensões e reconstruções sobre os discursos apresentados e temas investigados. Essa análise é composta por três partes, que consistem na unitarização, também chamada de desmontagem de textos; na categorização, que engloba o ato de produzir categorias através do estabelecimento de relações entre as unidades; e, por fim, a produção de metatextos através da captação do novo emergente.

Seguindo as ideias de Moraes e Galiazzi (2016), procedemos com o processo de categorização das unidades de significado, perpassando pelos três níveis de categorização estabelecidos. Primeiramente, obtivemos, de forma emergente, 10 categorias classificadas como iniciais, que agruparam 165 unidades de significado. Após as comparações entre as categorias iniciais, estabelecemos aproximações entre elas e obtivemos, também de forma emergente, cinco categorias classificadas como intermediárias, estas foram denominadas da seguinte forma: (1) Desenvolvimento das práticas docentes na educação básica; (2) A abordagem por temas e a interdisciplinaridade no ensino e aprendizagem; (3) Possibilidades e desafios no processo de formação continuada; (4) Compreensões de professores sobre o enfoque CTS; (5) Autonomia do professor e as configurações curriculares.

Por fim, aproximamos os dois métodos em um único processo de análise. Segundo Moraes e Galiazzi (2016, p. 46), "partindo de categorias definidas "a priori" com base em teorias escolhidas previamente, o pesquisador encaminha transformações gradativas no conjunto inicial de categorias". Após a aproximação das categorias intermediárias, não apareceram categorias emergentes para além das duas categorias definidas a priori, denominadas da seguinte forma: (1) Possibilidades e desafios da abordagem CTS no processo de formação continuada; (2) Desenvolvimento das práticas docentes com orientação CTS na educação básica. 


\section{Resultados}

Com os dados anteriormente apresentados, criou-se o Quadro 1, que organiza os 11 trabalhos, em ordem cronológica de publicação, e indica o título, autor(a) e Instituição na qual foi desenvolvida a pesquisa. Para facilitar a análise, os trabalhos foram identificados por códigos, as dissertações são chamadas de "D", seguidas da numeração em ordem cronológica, e as teses são identificadas com "T", seguindo a mesma linha de pensamento cronológico.

Quadro 1 - Teses e Dissertações BDTD

\begin{tabular}{|c|c|c|c|c|c|}
\hline $\mathbf{N}^{\mathbf{o}}$ & Título & Autor & Ano & $\begin{array}{l}\text { Dissertação } \\
\text { Ou tese }\end{array}$ & Instituição \\
\hline D1 & $\begin{array}{l}\text { A chuva ácida na perspectiva de } \\
\text { tema social: um estudo com } \\
\text { professores de química em } \\
\text { Criciúma (SC) }\end{array}$ & $\begin{array}{l}\text { Juliana } \\
\text { Cardoso } \\
\text { Coelho }\end{array}$ & 2005 & Dissertação & $\begin{array}{l}\text { Universidade } \\
\text { Federal de Santa } \\
\text { Catarina }\end{array}$ \\
\hline D2 & $\begin{array}{l}\text { Estudo das concepções de } \\
\text { professores da área de ciências } \\
\text { naturais sobre as interações } \\
\text { entre ciência, tecnologia e } \\
\text { sociedade }\end{array}$ & $\begin{array}{l}\text { Elisangela } \\
\text { Matias } \\
\text { Miranda }\end{array}$ & 2008 & Dissertação & $\begin{array}{l}\text { Universidade } \\
\text { Federal de São } \\
\text { Carlos }\end{array}$ \\
\hline D3 & $\begin{array}{l}\text { Abordagem CTS no ensino } \\
\text { médio: um estudo de caso da } \\
\text { prática pedagógica de } \\
\text { professores de biologia }\end{array}$ & $\begin{array}{l}\text { Karolina } \\
\text { Martins } \\
\text { Almeida e } \\
\text { Silva }\end{array}$ & 2010 & Dissertação & $\begin{array}{l}\text { Universidade } \\
\text { Federal de Goiás }\end{array}$ \\
\hline D4 & $\begin{array}{l}\text { Conceitos de ciências para } \\
\text { educação do campo a partir do } \\
\text { tema agriculturas }\end{array}$ & $\begin{array}{l}\text { Maria José } \\
\text { Aguiar dos } \\
\text { Reis Silva. }\end{array}$ & 2014 & Dissertação & $\begin{array}{l}\text { Universidade de } \\
\text { Brasília }\end{array}$ \\
\hline D5 & $\begin{array}{l}\text { A história das ciências no } \\
\text { ensino de química: implicações } \\
\text { para uma abordagem CTS na } \\
\text { formação continuada de } \\
\text { professores }\end{array}$ & $\begin{array}{l}\text { Rosangela } \\
\text { Rodrigues } \\
\text { de Oliveira }\end{array}$ & 2016 & Dissertação & $\begin{array}{l}\text { Universidade } \\
\text { Federal do ABC }\end{array}$ \\
\hline D6 & $\begin{array}{l}\text { Educação CTS e } \\
\text { interdisciplinaridade: } \\
\text { perspectivas para professores do } \\
\text { ensino médio }\end{array}$ & $\begin{array}{l}\text { Roseane } \\
\text { Freitas } \\
\text { Fernandes }\end{array}$ & 2016 & Dissertação & $\begin{array}{l}\text { UNIVERSIDADE } \\
\text { DE BRASÍLIA }\end{array}$ \\
\hline D7 & $\begin{array}{l}\text { Ensino de ecologia sob a } \\
\text { perspectiva CTS e investigativa: } \\
\text { um caminho para o letramento } \\
\text { científico }\end{array}$ & $\begin{array}{l}\text { Bruna } \\
\text { Lorena } \\
\text { Valentim da } \\
\text { Hora }\end{array}$ & 2017 & Dissertação & $\begin{array}{l}\text { Universidade } \\
\text { Federal do Rio } \\
\text { Grande do Norte }\end{array}$ \\
\hline $\mathrm{T} 1$ & $\begin{array}{l}\text { A abordagem CTS no contexto } \\
\text { da formação e da atuação dos } \\
\text { professores da área de Ciências } \\
\text { da Natureza }\end{array}$ & $\begin{array}{l}\text { Jucelino } \\
\text { Cortez }\end{array}$ & 2018 & Tese & $\begin{array}{l}\text { Universidade } \\
\text { Federal do Rio } \\
\text { Grande do Sul }\end{array}$ \\
\hline
\end{tabular}




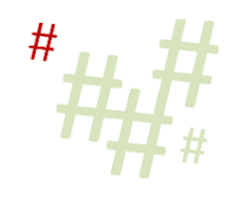

\begin{tabular}{|c|l|l|l|l|l|}
\hline T2 & $\begin{array}{l}\text { Enfoque Ciência, Tecnologia e } \\
\text { Sociedade (CTS): contribuições } \\
\text { para a profissionalização } \\
\text { docente }\end{array}$ & $\begin{array}{l}\text { Andrei } \\
\text { Steveen } \\
\text { Moreno } \\
\text { Rodríguez }\end{array}$ & 2018 & Tese & $\begin{array}{l}\text { Universidade } \\
\text { Federal do Rio } \\
\text { Grande do Sul }\end{array}$ \\
\hline D8 & $\begin{array}{l}\text { Abordagem de temas no ensino } \\
\text { de ciências: reflexões para } \\
\text { processos formativos de } \\
\text { professores }\end{array}$ & $\begin{array}{l}\text { Eril } \\
\text { Medeiros da } \\
\text { Fonseca }\end{array}$ & 2019 & Dissertação & $\begin{array}{l}\text { Universidade } \\
\text { Federal do Pampa }\end{array}$ \\
\hline D9 & $\begin{array}{l}\text { A influência do discurso } \\
\text { docente na construção da visão } \\
\text { de ciência dos estudantes } \\
\text { alinhada aos objetivos do } \\
\text { enfoque CTS }\end{array}$ & $\begin{array}{l}\text { Karine de } \\
\text { Cássia } \\
\text { Prado } \\
\text { Batista }\end{array}$ & 2019 & Dissertação & $\begin{array}{l}\text { Universidade } \\
\text { Federal de Itajubá }\end{array}$ \\
\hline
\end{tabular}

Fonte: Kist; München (2020).

Destaca-se que as pesquisas nessa área estão concentradas, predominantemente, nos últimos cinco anos, evidenciando que os programas de pós-graduação têm se dedicado às temáticas que envolvem as práticas de professores de Ciências, nesses últimos anos. Essa observação é corroborada pelas ideias de Santos e Auler (2011, p. 25), quando defendem que, "no Brasil, os primeiros trabalhos com a denominação CTS no ensino de Ciências surgiram na década de 1990 e hoje o número de publicações na área tem expandido significativamente". Além disso, os trabalhos concentram-se, sobretudo, nas regiões centro-oeste, sul e sudeste.

A seguir, apresentamos as categorias finais e os metatextos utilizados nesta pesquisa. Os excertos utilizados no decorrer da escrita serão referenciados com o código que diferencia teses de dissertações, seguido do nome do autor, do ano da publicação e, quando necessário, da página da qual foram extraídos.

\subsection{Possibilidades e desafios da abordagem CTS no processo de formação continuada}

A primeira categoria, intitulada Possibilidades e desafios da abordagem CTS no processo de formação continuada, foi elaborada, a priori, e nela foram contempladas 98 unidades de significado, que fazem parte de três categorias intermediárias, oriundas das teses e dissertações analisadas, nomeadas e ordenadas numericamente, da seguinte forma: (3) Possibilidades e desafios no processo de formação continuada; (4) Compreensões de professores sobre o enfoque CTS; (5) Autonomia do professor e as configurações curriculares. Estas unidades de significado deram origem aos metatextos propostos a seguir, que, conforme Moraes e Galiazzi (2016), objetivam explicitar uma nova compreensão que se apresenta por meio da combinação dos elementos.

A formação inicial dos professores é o alicerce de suas práticas, sendo o aparato principal para que os mesmos exerçam suas funções em sala de aula. Com o passar dos anos, os projetos de formações das Licenciaturas foram reformulados com a finalidade de englobar eixos e panoramas necessários para que o ensino e aprendizagem ocorram de forma coerente com as exigências das legislações. Bem como é declarado nas Diretrizes Curriculares Nacionais para a formação inicial em nível superior (2015), 
os cursos de formação deverão garantir nos currículos conteúdos específicos da respectiva área de conhecimento ou interdisciplinares, seus fundamentos e metodologias, bem como conteúdos relacionados aos fundamentos da educação, formação na área de políticas públicas e gestão da educação, seus fundamentos e metodologias, direitos humanos, diversidades étnico-racial, de gênero, sexual, religiosa, de faixa geracional, Língua Brasileira de Sinais (Libras), educação especial e direitos educacionais de adolescentes e jovens em cumprimento de medidas socioeducativas (BRASIL, 2015, p. 11).

Partindo da análise das dissertações e teses, é possível visualizar um panorama de como as formações iniciais e continuadas se processam em relação à Educação CTS, com isso percebemos como é o perfil dos profissionais que estão sendo formados para trabalhar nas escolas. Também foi possível observar quais as compreensões que os professores possuem sobre os pressupostos do enfoque CTS e como esses pressupostos estão (ou não) sendo trabalhados nos programas de formação continuada.

Com base nos excertos da dissertação 1, podemos destacar que esses condizem diretamente com a preocupação a respeito do perfil dos profissionais que vão para a escola. Nessa são apontados aspectos "possíveis de serem contemplados para contribuir com a abordagem de temas como prerrogativa de formação continuada" ( $\mathrm{D}_{1}, \mathrm{COELHO}, 2005$, p. 13). Corroborando com esse excerto, destacamos D4, quando a autora refere-se ao método tradicional de ensino como "a pedagogia desconexa da vida do estudante, onde ocorre a falta de recursos e espaços" ( $\mathrm{D}_{4}$, SILVA, 2014, p. 14). Essa ressalta, ainda, que o atual panorama vem modificando-se e que, para isso ocorrer, de fato, deve haver iniciativas, como, por exemplo, as propostas de formação continuada.

Ainda em $\mathrm{D}_{4}$, destacamos alguns excertos que remetem à preocupação com os programas de formação continuada voltados para a educação CTS, quando a autora descreve, em sua pesquisa, sobre a importância de se considerar "em cursos de formação continuada as discussões sobre CTS no ensino de Ciências" ( $\mathrm{D}_{4}$, SILVA, 2014, p. 121). Tendo em vista a relevância dada ao assunto, a mesma autora corrobora com o excerto acima, destacando que "este enfoque possibilita discutir concepções de cidadania, modelos de sociedade e desenvolvimento científico e tecnológico" ( $\mathrm{D}_{4}$, SILVA, 2014, p. 121).

A formação inicial deficitária acarreta em uma prática engessada na perspectiva conteudista e tradicional, incessantemente reafirmada na pesquisa da $D_{6}$, quando os participantes salientam que, muitas vezes, a formação inicial dificulta a realização de um trabalho interdisciplinar nas escolas, pois muitos tiveram uma formação puramente compartimentada e linear e, por isso, sentem dificuldades em relacionar e dialogar com outras disciplinas, assim como trabalhar numa ação coletiva ( $D_{6}$, FERNANDES, 2016).

O ensino interdisciplinar é de suma importância para englobar a aprendizagem de forma a alcançar a alfabetização científica. Nóvoa (1995) afirma que o diálogo entre os professores e a criação de redes de trabalho inter-relacionadas constituem um fator decisivo na afirmação de valores próprios da profissão docente e na consolidação de saberes emergentes da prática profissional, sendo que essas redes emergem de formações continuadas e contínuas, através das discussões promovidas entre os grupos.

Os debates sobre interdisciplinaridade dentro do contexto da educação aumentaram no decorrer dos últimos anos. Feistel (2012) destaca que as mudanças ocorridas na sociedade se vinculam ao enfoque para a interdisciplinaridade, explicando que essas "desencadearam a fragmentação do conhecimento e o predomínio das especializações que, por sua vez, remetem à necessidade de haver um conhecimento mais global e integrado" (FEISTEL, 2012, p. 71). 
Corroborando com os excertos da $\mathrm{D}_{6}$, também podemos evidenciar traços dessa preocupação em $D_{7}$, quando a autora afirma que os cursos de formação inicial devem fornecer meios para que os futuros docentes consigam enfrentar os problemas que podem surgir na prática docente, e a formação continuada deve entrar como meio de ajudar os docentes a superar os obstáculos que ainda permanecem, advindos da formação inicial $\left(\mathrm{D}_{7}, \mathrm{HORA}\right.$, 2017).

Referente à formação calcada nas inter-relações do enfoque CTS, percebemos preocupações assinaladas em todas as pesquisas analisadas. A $T_{1}$ salienta que, nos cursos de formação, os professores são orientados a acompanhar e utilizar inovações associadas à ciência e à tecnologia ( $T_{1}$, CORTEZ, 2018). Nessa, ainda é ressaltada a importância em formar educadores motivados, que não tenham medo de inovar e incentivar o "despertar crítico, ético e cidadão das futuras gerações" (T1, CORTEZ, 2018, p. 97).

Para que tenhamos docentes que consigam trabalhar com o enfoque CTS em suas aulas, esses precisam passar por uma formação inicial e/ou continuada que englobe essas inter-relações, assim como trata a $\mathrm{T}_{2}$. Esses processos devem desenvolver melhores meios de pensar e atuar para que o desempenho docente seja realizado de modo crítico e com ênfase na autonomia ( $\mathrm{T}_{2}$, RODRÍGUEZ, 2018), para que, dessa forma, seja caracterizada a influência do enfoque CTS no processo de profissionalização docente.

Com a participação dos professores em cursos que trabalham com as relações CTS, na $\mathrm{T}_{2}$ foi possível a identificação de uma série de características e aportes do processo formativo nesse enfoque. Assim como o autor afirma ao descrever que "os processos de formação inicial e continuada na perspectiva do enfoque CTS, constituem-se em espaços que permitirão aos professores desenvolver melhores formas de pensar e atuar para desempenhar a profissão docente de forma crítica" ( $\mathrm{T}_{2}$, RODRÍGUEZ, 2018, p. 16).

A participação em programas de formação continuada tende a contribuir significativamente para a profissionalização de todos os docentes envolvidos, aspecto afirmado em $\mathrm{D}_{8}$, quando o autor discorre a respeito da formação, afirmando que,

articular essa formação, capaz de proporcionar a tomada de consciência e participação em decisões de cunho social dos estudantes mobiliza também um saber-fazer dos professores, ou seja, a formação crítica do estudante está relacionada à formação e desenvolvimento do trabalho do docente ( $\mathrm{D}_{8}$, FONSECA, 2019, p. 34).

O discurso docente voltado para o enfoque CTS, em $\mathrm{D}_{9}$, é apresentado como uma das alternativas para a alfabetização científico-tecnológica, pois critica e reforça que a postura dos professores deve ser modificada, tornando-se menos autoritária, de forma a oferecer ao aluno uma participação na construção do conhecimento desenvolvido ( $\mathrm{D}_{9}$, BATISTA, 2019). De acordo com Chassot, "a alfabetização científica pode ser considerada como uma das dimensões para potencializar alternativas que privilegiam uma educação mais comprometida" (CHASSOT, 2003 p. 91).

Percebemos, nas pesquisas, a constante preocupação tanto com a formação inicial quanto com a continuada, pautadas, principalmente, no perfil dos professores que estão sendo inseridos nas escolas e com o tipo de abordagem metodológica que esses docentes vão empregar em suas aulas. A ideia de desvencilhar-se da prática engessada no ensino compartimentado para facilitar a busca pela aprendizagem interdisciplinar também teve grande destaque, externado principalmente pela sua relação com a educação CTS. 
Outro assunto fortemente abordado foi a ocorrência de programas de formação continuada e se esses são direcionados para essa temática. Os trabalhos pesquisados inferem que as formações ocorrem regularmente, porém, em sua grande maioria, as temáticas não se voltam para aspectos da educação CTS, não se têm espaços e recursos para a promoção de uma formação voltada para cada área do conhecimento.

Após a leitura das dissertações e teses que compõe este artigo, constatamos que apenas as dissertações $D_{5}$ e $D_{6}$ realizaram cursos ou oficinas com os professores, voltados para a temática CTS. A $\mathrm{D}_{5}$ realizou a pesquisa por meio de uma oficina que obteve resultados bastante significativos, apontando as possibilidades e dificuldades da inserção da história das ciências (HC), sob enfoque CTS no ensino de química, em especial à formação continuada de professores.

A dissertação $\mathrm{D}_{6}$ trouxe concepções oriundas de um curso de formação continuada, no qual observou-se que os professores compreendem a importância da educação pautada no enfoque CTS, mas, ao mesmo tempo, demonstram incertezas referentes a este trabalho. As incertezas giram em torno da falta de preparo e também da falta de tempo para "passar" todos os conteúdos anuais e, ainda, trabalhar com temas voltados ao enfoque CTS.

As compreensões dos professores sobre a temática proposta nesta análise também foram objeto de investigação da autora de $\mathrm{D}_{6}$, que ressalta em sua pesquisa que,

\begin{abstract}
os professores reconhecem que ainda tem muitos professores que não compreendem o que é Educação CTS, tornando-se um desafio convencer os demais colegas a trabalharem nessa perspectiva. Segundo os professores, muitos preferem manter a habitual prática pedagógica que vem exercendo ao longo dos anos em sala de aula, principalmente, os professores que tem mais tempo de regência, pois geralmente demonstram não terem a mesma disposição e motivação de trabalho como nos primeiros anos de exercício profissional ( $\mathrm{D}_{6}$, FERNANDES, 2016, p. 121).
\end{abstract}

Ressalta-se, ainda, que a formação continuada voltada para a educação CTS daria conta de problematizar, muitas vezes, os resquícios de uma formação conteudista e tradicional, deixando os professores mais seguros para trabalhar com a utilização da abordagem temática em sala de aula. A formação continuada deve desenvolver e encorajar nos professores a autonomia necessária para suprir a atual necessidade educacional.

Santos e Mortimer (2002), ao descreverem sobre as reformulações curriculares, afirmam que,

isso evidencia que a reforma curricular atual do ensino médio depende de um processo de formação continuada de professores para que não se torne letra morta na legislação. Como desenvolver novos modelos curriculares sem envolver aqueles que irão aplicar tais modelos? Não adianta apenas inserir temas sociais no currículo, sem qualquer mudança significativa na prática e nas concepções pedagógicas [...] (SANTOS; MORTIMER, 2002, p. 127).

Repensar a formação continuada de professores é uma das formas de construir uma postura crítica/reflexiva nos docentes da educação básica, assim como expresso em D5, essa implica em buscar por respostas aos desafios decorrentes das novas relações entre a Ciência, a Tecnologia e a Sociedade. A pesquisa $\mathrm{D}_{5}$ ainda nos remete à formação continuada quando 
infere que o professor crítico reflexivo é aquele que não se estabiliza no conhecimento, que "busca incansavelmente sua evolução formativa" ( $\mathrm{D}_{5}$, OLIVEIRA, 2016, p. 86).

Portanto, ao discorrer sobre a formação continuada, nos remetemos a pensar nos espaços e no estímulo para que ocorram, assim como afirmam Radetzke e Güllich (2020),

\begin{abstract}
estimular processos de formação continuada como sendo espaços e tempos para discussão, em que os docentes possam adquirir consciência sobre seus processos de formação e assim de suas concepções de docência, refletindo sobre as mesmas, dialogando com seus pares e com referenciais (RADETZKE; GÜLLICH, 2020, p. 22).
\end{abstract}

Ao mencionarmos a postura crítica dos docentes, também almejamos a criticidade dos alunos, afinal não queremos que os estudantes apenas compreendam seu cotidiano de forma simplista, mas que também sejam críticos aos assuntos que envolvam ciência e tecnologia. Por fim, as teses e dissertações analisadas, majoritariamente, discorrem a respeito da necessidade de redirecionar os cursos de formação continuada para a compreensão dos elementos que embasam a Educação CTS, e sua intencionalidade em abordar problemáticas de caráter científico-tecnológicas do mundo contemporâneo, ao considerar a importância de mudanças no ensino para que o mesmo deixe de ser conteudista e fragmentado.

\title{
3.2 Desenvolvimento das práticas docentes com orientação CTS na educação básica
}

Esta segunda categoria, denominada desenvolvimento das práticas docentes com orientação CTS na educação básica, é composta por 67 unidades de significados e duas categorias intermediárias, denominadas e codificadas do seguinte modo: (1) Desenvolvimento das práticas docentes na educação básica; (2) A abordagem por temas e a interdisciplinaridade no ensino e aprendizagem. Destas categorias, surgiram os metatextos apresentados a seguir, que, segundo Moraes e Galiazzi (2016), surgem após a eliminação do excesso de informações e apresentam os fenômenos de forma sintética e ordenada.

A formação docente inicial, como anteriormente mencionada, tem influência marcante nas atitudes dos professores em sala de aula. Se esse foi formado com uma perspectiva tradicional e conteudista, será fortemente marcado por ela nas abordagens e metodologias em suas aulas. Compreende-se que a formação inicial está ligada à prática docente, assim como o ambiente profissional e as condições de trabalho são fortalecedores de algumas dessas práticas.

Corroborando o excerto acima citado, destacamos as ideias de Carvalho e Gil-Pérez (1995), quando discorrem a respeito da formação, afirmando que

\footnotetext{
é importante assinalar esta diferença, porque mostra até que ponto as carências e os erros que evidenciam nossa formação não são o resultado de incapacidades essenciais, pois ao se proporcionar aos professores a oportunidade de um trabalho coletivo de reflexão, debate e aprofundamento, suas produções podem aproximar-se aos resultados da comunidade científica. Trata-se, e então, de orientar o trabalho de formação dos professores como pesquisa dirigida, contribuindo assim, de forma funcional e efetiva, para transformação de suas concepções iniciais. (CARVALHO; GIL-PÉREZ, 1995, p. 15).
} 
Em nossa análise, constatamos, em $\mathrm{D}_{1}$, que muitas vezes o ponto de estagnação do ensino e aprendizagem é a falta de coerência na prática docente, e acredita-se que se a inserção dos pressupostos da educação CTS acontecerem de forma sutil e gradativa, o professor não se mostrará tão resistente, uma vez que, em geral, os professores não se sentem preparados para essa tarefa. Em $\mathrm{D}_{3}$ podemos observar a mesma preocupação expressa nas falas dos professores, quando esses externam seus anseios referentes à prática pedagógica e aos trabalhos com a abordagem CTS, expondo que consideram importante trabalhar nessa abordagem, mas que também enfrentam dificuldades, pois não tiveram a formação necessária para tal.

De acordo com München (2016, p. 60), “o modo de abordagem da ciência nos espaços escolares está vinculado ao entendimento que os professores possuem, portanto se torna relevante investigar as suas compreensões". Nesse sentido, destacamos o excerto de $\mathrm{D}_{3}$ sobre as compreensões equivocadas em se trabalhar a abordagem CTS quando

identificamos compreensões restritas que dizem respeito a utilização de aparatos tecnológicos, ou seja, de compreender que trabalhar com recursos tecnológicos (aparelho multimídia e microscópio, por exemplo) no ambiente educativo é proporcionar aos educandos um entendimento das relações entre a Ciência, Tecnologia e Sociedade ( $\mathrm{D}_{3}$, SILVA, 2010, p. 123).

A abordagem tradicional também foi fortemente externada em $\mathrm{D}_{3}$, mesmo os professores utilizando-se de tecnologias, como multimídias e outros aparatos tecnológicos, ainda estava explícita a metodologia de aulas expositivas, sem relação dos conceitos científicos com a realidade ( $\mathrm{D}_{3}$, SILVA, 2010), sem a promoção da mediação, acarretando na limitação de saberes, o que se contrapõe às ideias de Vigotski (2011), quando o mesmo afirma que a aprendizagem acontece por meio da mediação e interação com o outro.

Também em $\mathrm{D}_{3}$, assinalou-se alguns entendimentos mais amplos sobre as relações com o enfoque CTS, indicando que alguns docentes entendem a necessidade de reestruturação nos currículos, como evidenciado neste excerto: "o currículo deveria 'abrir espaço' para que os docentes pudessem trabalhar com temas" ( $\mathrm{D}_{3}$, SILVA, 2010, p. 105). Esse espaço no currículo poderá propiciar a prática docente calcada em temas problematizadores do cotidiano dos alunos, juntamente com a promoção de reuniões interdisciplinares para discussão dos trabalhos que serão realizados.

Strieder e Kawamura (2017) afirmam que, quando a abordagem temática é implantada no sistema de ensino,

as preocupações voltam-se à forma de facilitar o entendimento dos conteúdos curriculares, sobretudo através de exemplos, sem necessariamente questionar a seleção e o papel dos conteúdos curriculares já estabelecidos. De certa forma, parte-se do pressuposto de que o conhecimento escolar é algo dado, cabe encontrar maneiras de abordá-lo e permitir ao aluno perceber seu significado [...] especificamente no que se refere às discussões CTS, nesse caso, os aspectos mais amplos relacionados à ciência, à tecnologia e/ou à sociedade contribuem para contextualizar o conhecimento científico a ser trabalhado, buscando uma aproximação com a vivência cotidiana do aluno [...] (STRIEDER; KAWAMURA, 2017, p. 43). 
Reforçando a ideia de se trabalhar com a abordagem temática, destacamos as afirmações propostas por Halmenschlager e Delizoicov (2017), quando discorrem sobre a importância de selecionar conteúdos que estejam diretamente ligados a alguma temática que represente uma situação real no contexto dos alunos. A utilização de temáticas próximas da realidade dos alunos possibilita o entendimento e engajamento desses estudantes no assunto que está sendo trabalhado, promovendo, assim, a aprendizagem significativa.

Ainda ressaltando a importância de se trabalhar com a abordagem temática, destacamos que sempre é possível estabelecer relações entre os temas e os conteúdos científicos que são utilizados diretamente em sala de aula. Halmenschlager e Delizoicov (2017) afirmam que,

\begin{abstract}
ao analisar a relação entre o tema e o conteúdo a ser desenvolvido, pode-se afirmar que se busca o estabelecimento de articulações, mediadas por Temas Geradores, entre o contexto sociocultural e os conceitos científicos, possibilitando a significação destes e a abordagem de conteúdos que contemplam aspectos sociais, culturais, ambientais e políticos (p. 314).
\end{abstract}

Corroborando as ideias de Ferrão e Auler (2012), ao mencionarem que, quando o planejamento é voltado para o currículo a ser cumprido, e não para as experiências do aluno, esse é excluído de qualquer participação em tomadas de decisões. Englobando o currículo como forma de auxiliar na modificação da prática pedagógica, trouxemos as ideias de $T_{1}$, ao relatar que o currículo deve ter caráter multidisciplinar, com observância nos contextos social e cultural, instigando os estudantes a elaborarem a capacidade de posicionamento frente à resolução de problemas oriundos da sociedade $\left(\mathrm{T}_{1}\right.$, CORTEZ, 2018).

Em $\mathrm{D}_{4}$ reforça-se a ideia de trabalho coletivo como forma de modificar o modo de pensar sobre as áreas de conhecimento e introduzir a interdisciplinaridade para superar a visão simplista e ingênua, proposta pelo ensino tradicional $\left(\mathrm{D}_{4}\right.$, SILVA, 2014). Trecho que nos remete às ideias de München (2016), quando a autora descreve que a abordagem CTS auxilia no rompimento dessa visão, proporcionando a reflexão sobre a prática educativa.

A busca pelo aprimoramento das práticas pedagógicas é descrita em $\mathrm{D}_{6}$, quando se pensa na elaboração de projetos interdisciplinares que envolvam as relações do enfoque CTS a fim de promover uma "educação CTS que traz pressupostos fundamentais para uma formação que contemple a compreensão crítica em torno do modelo de desenvolvimento científico e tecnológico" ( $\mathrm{D}_{6}$, FERNANDES, 2016, p. 28), superando a ideia de ciência ingênua e simplista.

Ao tratar do enfoque CTS, em $\mathrm{D}_{6}$, nos deparamos com a ideia de utilização do enfoque como forma de motivação em sala de aula. Expressando também contradições a isso, $\mathrm{D}_{6}$ reforça que pensar apenas em motivação foge dos objetivos do ensino na perspectiva CTS ( $\mathrm{D}_{6}$, FERNANDES, 2016). Assim como afirmam Santos e Schnetzler (2010, p. 75), esses objetivos relacionam-se "à solução de problemas da vida real que envolvem aspectos sociais, tecnológicos, econômicos e políticos, o que significa preparar o indivíduo para participar ativamente na sociedade democrática".

Referente aos objetivos incorporados em uma educação com enfoque CTS, $\mathrm{T}_{2}$ reafirma que "a contextualização a partir de uma perspectiva com enfoque CTS consiste em abordar temas e/ou problemáticas atuais do meio, com o objetivo de produzir novos conhecimentos e reflexões críticas a respeito de tais situações" ( $\mathrm{T}_{2}$, RODRÍGUEZ, 2018, p. 128). Em 
consonância com o excerto acima apresentado, concordamos que trabalhar com temas favorece a formação integral dos estudantes e a tomada de decisões.

$\mathrm{O}$ excerto acima vai ao encontro do relatado em $\mathrm{D}_{7}$, quando emergem descrições sobre o posicionamento do estudante, dando ao ensino de ciências este papel de mostrar ao aluno que ele pode agir no mundo com os conhecimentos construídos nas aulas de ciências, sendo que a conscientização dos discentes sempre será o ponto crucial para que os mesmos entendam seu posicionamento perante a sociedade. De acordo com $\mathrm{D}_{7}$,

\footnotetext{
dirigem-se os olhos para a crença de que a abordagem CTS e investigativa sejam um caminho profícuo para uma educação científica embasada nas discussões sociopolíticas; econômicas e científicas, que possa propiciar uma formação mais crítica, emancipatória, que possibilita meios para que o aluno possa intervir em sua vida cotidiana ( $\mathrm{D}_{7}, \mathrm{HORA}, 2017$, p. 109).
}

A postura do professor mediante o ensino calcado no enfoque CTS também é expressa em $\mathrm{T}_{2}$, ao relatar que, além da modificação na postura do aluno, que deixa de ser passivo e age como produtor de conhecimentos, o professor também deve se colocar em outra posição, passando a agir como mediador ativo, com convicção de suas concepções sobre a temática ( $\mathrm{T}_{2}$, RODRÍGUEZ, 2018). Neste caso, os questionamentos de ambas as partes são primordiais para o processo de ensino e aprendizagem.

Ainda em $\mathrm{T}_{2}$, relatou-se pontos positivos para a prática docente após a aplicação de uma sequência didática com enfoque CTS. Esses pontos englobam "o planejamento de atividades de forma coerente e contextualizada, a pesquisa, o trabalho colaborativo, a formação sócio-política, a responsabilidade social e o desenvolvimento do pensamento crítico" ( $T_{2}$, RODRÍGUEZ, 2018, p. 150).

Sobre as compreensões dos professores, na maioria, apresentam-se vinculadas a uma abordagem conceitual para o ensino de ciências, em que se percebe a inserção de questões do contexto, porém, para contribuir no entendimento de conteúdos como forma de facilitar a aprendizagem. $\mathrm{O}$ estudo realizado na $\mathrm{D}_{8}$ contrapõe essas compreensões, ressaltando que é pertinente uma abordagem de temas que carregue implicações sociais da vida dos sujeitos, enquanto forma de estruturar e complementar o contexto da prática pedagógica $\left(D_{8}\right.$, FONSECA, 2019).

A abordagem por temas, conforme mencionado anteriormente, tem o intuito de complementar a prática pedagógica. Em $\mathrm{D}_{8}$, destacamos um excerto sobre as diferenças nas compreensões dessa abordagem, ao defender que, "diante disso percebi uma contradição na intencionalidade das mesmas em relação à proposição dos conteúdos, ou seja, concepções que oscilam entre uma abordagem temática e abordagem conceitual" ( $\mathrm{D}_{8}$, FOSNECA, 2019, p. 46).

Referente a criticidade que se almeja desenvolver nos alunos, $\mathrm{D}_{9}$ afirma que o docente deve assumir postura crítica frente aos conteúdos e, principalmente, à sua prática, sendo responsável por levar elementos construtivos para o desenvolvimento da reflexão e responsabilidade social do aluno ( $\mathrm{D}_{9}$, BATISTA, 2019). Contudo, coloca-se o docente como a peça fundamental para a elaboração de objetivos e métodos capazes de realizar mudanças significativas no ensino.

Mediante o discurso dos professores, $\mathrm{D}_{9}$ coloca que "o docente que utiliza da abordagem CTS tende a possuir um discurso menos autoritário em sala de aula, de forma a 
oferecer ao aluno uma participação na construção do conhecimento desenvolvido" ( $\mathrm{D}_{9}$, BATISTA, 2019, p. 95). Ressalta-se, ainda, que o professor deve encontrar momentos oportunos para a realização de reflexões e desenvolvimento de processos que abrangem os objetivos do enfoque CTS. Um dos pontos mais comentados nas dissertações e teses analisadas são os relatos de falta de compreensão dos conceitos relevantes, quando falamos em educação CTS. Pelo exposto nas pesquisas analisadas, a prática docente está vinculada às compreensões sobre CTS, portanto, esse ponto influencia diretamente em não utilizar essa abordagem em aula.

Apesar de a falta de conhecimento na área da educação CTS, a maioria dos trabalhos considera que o enfoque sugerido é importante por utilizar a abordagem temática com intuito de chegar ao conceito científico. Os professores pesquisados nas teses e dissertações entendem a necessidade, mas nem sempre conseguem fazer uso dessa, devido a falta de formação, e, na maioria das vezes, também a falta de tempo. Alguns relatam, ainda, que fazem uso de tecnologias digitais em sala de aula como um mecanismo de apoio para a aprendizagem, porém esse ainda é feito de forma bastante tradicional.

Como práticas utilizadas, observamos, também, a utilização de sequências didáticas calcadas nos conceitos CTS, as quais trouxeram conhecimentos significativos para os alunos, pois foram mediadas e conseguiu-se aproximar os conceitos do cotidiano com os conteúdos nelas trabalhados. De acordo com Zabala (1998), as sequências didáticas apresentam elementos, como conjuntos de atividades estruturadas para a realização de certos objetivos educacionais, que são conhecidos tanto pelo professor como pelos alunos. A abordagem do enfoque CTS, através de sequências didáticas, vai ao encontro do ideal de abordar os conteúdos por meio de temáticas oriundas do cotidiano dos alunos.

A utilização de conteúdos do cotidiano, muitas vezes, aparece como forma de exemplificação do conceito que se pretende ensinar, porém, podemos afirmar que o caminho é outro na abordagem CTS. De acordo com Strieder e Kawamura (2017),

[...] nas propostas de práticas educacionais, essa ênfase associa-se à discussão de temas que estão em pauta na mídia ou no dia-a-dia dos alunos, com a intenção de contribuir para que os alunos os reconheçam e compreendam como esses se articulam ou se associam à ciência e à tecnologia [...] (STRIEDER; KAWAMURA, 2017, p. 40).

A abordagem CTS, segundo Auler (2011), segue um percurso distinto do utilitarista e instrumental. Nessa, busca-se a construção de níveis mais abstratos de pensamento, superando a ideia de que na escola há apenas reprodução e apropriação de conhecimentos, afirmando que "os conteúdos disciplinares vêm depois. Assumem o papel de 'ferramentas culturais' que, tal qual faróis, ajudam a iluminar o problema, projetam luz sobre a controvérsia a partir de vários ângulos" (AULER, 2011, p. 92).

Outro ponto bastante ressaltado foi sobre a postura crítica, tanto dos alunos como dos professores. Os alunos devem posicionar-se criticamente perante as adversidades do dia a dia, comentando e questionando durante as aulas para que ocorra a mediação e o professor deixe de lado a postura autoritária, dando voz aos estudantes.

Por fim, sugere-se a reformulação dos currículos escolares, agregando a eles o caráter interdisciplinar, pois, de acordo com Feistel (2012), a interdisciplinaridade é "a busca de contextualização dos conteúdos de ensino de forma mais significativa" (FEISTEL, 2012, 
p.71). A prática docente é desenhada de acordo com o currículo norteador da escola, portanto, com a modificação do currículo, como, por exemplo, a implementação da Base Nacional Comum Curricular (BNCC), consequentemente, poderá ocorrer a modificação da prática. Considerando a BNCC como documento norteador da prática pedagógica, cabe-nos questionar se esse irá promover um espaço de debates para que ocorram as modificações necessárias nas práticas dos professores.

\section{Conclusão}

A investigação apresentada ressalta o interesse e a necessidade de pesquisar sobre a formação continuada dos professores da área de ciências da natureza e a sua atuação docente. Essa necessidade é aparente quando menciona-se a falta de compreensão sobre o enfoque CTS, oriunda de uma formação inicial que não trabalhava esses conceitos, dirigindo-se para a formação continuada, que poderia ser o aporte necessário para implementar a falta de conhecimentos relacionados a CTS.

Os programas de formação continuada ocorrem periodicamente, e a preocupação levantada está ligada às temáticas desses programas e a forma com que eles são desenvolvidos. Na maioria das vezes, não englobam os princípios do enfoque CTS, assim como também demandam de recursos, espaço e disponibilidade dos professores em participar. Como consequência da falta de formações e/ou de sua qualificação, evidencia-se a pouca compreensão dos pressupostos do enfoque CTS e, posteriormente, a não identificação dessa proposição em sala de aula.

A categoria 1, intitulada possibilidades e desafios da abordagem CTS no processo de formação continuada, trouxe aspectos extremamente relevantes para a discussão da formação continuada, evidenciou a necessidade dessa, principalmente voltadas para temáticas que fomentem processos de reorganização curricular. Nessa mesma categoria, evidenciou-se que seria importante a ocorrência de programas de formação continuada, voltados para os pressupostos do enfoque CTS, para que, assim, os professores fossem inseridos nesta perspectiva e caminhassem na direção desta abordagem em aula.

Inserir os professores na perspectiva do ensino baseado nos pressupostos da educação CTS tem como intuito instigar os mesmos a utilizar a abordagem temática em sala de aula. $\mathrm{O}$ enfoque CTS é um dos meios de reorganização curricular, portanto, essa discussão aflora a necessidade de o currículo ser construído com o ideal de visualizar e trabalhar com aspectos do cotidiano dos alunos, o que implicaria direta e positivamente no contexto de vida desses estudantes.

Sobre as práticas docentes, a categoria 2, chamada desenvolvimento das práticas docentes com orientação CTS na educação básica, evidenciou que, na maioria dos casos apresentados, os professores utilizam o cotidiano dos alunos para a explicação de um conceito e elencam isso ao enfoque CTS, mais uma vez retratando a falta de compreensão desses quanto a temática. $\mathrm{O}$ trabalho realizado nessa perspectiva precisa surgir de um problema do cotidiano dos alunos e, partindo dele, serão mediados e construídos os conceitos científicos.

Os professores, majoritariamente, têm uma grande preocupação com o tempo, o plano de trabalho, o cronograma das aulas e todos os conteúdos necessários para complementar a aprendizagem anual dos estudantes. A preocupação com os cronogramas de conteúdos, muitas vezes, impede que sejam utilizadas metodologias diversificadas de trabalho, pois essas demandam tempo para que ocorra a mediação e construção dos novos conceitos. 
Pensando nas implicações dos resultados desta pesquisa para o contexto atual, ressaltamos que esta externou resultados provocativos sobre a não utilização das inter-relações da Educação CTS em sala de aula, evidenciando a necessidade de se trabalhar, partindo desses pressupostos e objetivando a construção dos conceitos científicos. Pensando nas adversidades vividas, atualmente, e os resultados aqui apresentados, podemos citar que a prática docente, calcada na Educação CTS, promoveria o discernimento dos estudantes diante de vários aspectos, auxiliando os mesmos a interagir e interferir de forma positiva em seus contextos de atuação.

A atual situação de pandemia do novo coronavírus é um dos exemplos que podemos utilizar para discutir sobre a necessidade de se trabalhar a Educação CTS nas escolas. Analisando nosso contexto, podemos perceber que a falta de conhecimento pode ser um elemento significativo no controle da Pandemia. Como a Educação CTS relaciona-se com a Pandemia? Um trabalho baseado na abordagem temática em sala de aula propiciaria aos estudantes um maior conhecimento sobre vários aspectos da Pandemia, como o comportamento de um vírus, o funcionamento de uma vacina, a importância das regras de distanciamento social, o cuidado com as medidas de higiene, a desmistificação das Fake News, o papel da ciência e, principalmente, promoveria uma articulação entre Ciência, Tecnologia e Sociedade.

Como uma das evidências aqui discutidas, temos a necessidade das compreensões dos professores sobre sua prática docente e as inter-relações existentes com a educação CTS emergirem no cenário educacional. Por fim, destacamos que a abordagem educacional voltada para os pressupostos da educação CTS vem ao encontro dos anseios educacionais vivenciados atualmente, objetivando promover o ensino e a aprendizagem elencada aos temas experienciados no contexto dos alunos.

\section{Referências}

AULER, Décio. Novos Caminhos para a Educação CTS: ampliando a participação. In: SANTOS, Wildson Luiz Pereira dos; AULER, Décio (org.). CTS e a educação científica: desafios, tendências e resultados de pesquisas. Brasília: UnB, 2011. p. 73-97.

AULER, Décio; DELIZOICOV, Demétrio. Ciência-Tecnologia-Sociedade: relações estabelecidas por professores de ciências. Revista Electrónica de Enseñanza de las Ciencias. v. 5 n.2, 2006. Disponível em: http://reec.uvigo.es/volumenes/volumen5/ART8_Vol5_N2.pdf. Acesso em: 29 abr.2020.

BATISTA, Karine de Cássia Prado. Influência do Discurso Docente na Construção da Visão de Ciência dos Estudantes Alinhada aos Objetivos do Enfoque CTS. 2019.

Dissertação (Mestrado em Educação em Ciências). Curso de Pós-Graduação em Educação em Ciência, Universidade Federal de Itajubá, Itajubá, 2019. Disponível em:

https://repositorio.unifei.edu.br/xmlui/handle/123456789/2098. Acesso em: 29 abr. 2020.

\section{BRASIL, Diretrizes Curriculares Nacionais para a Formação de Professores da}

Educação Básica, em Nível Superior, Curso de Licenciatura, de Graduação Plena. RESOLUÇÃO No 2, DE $1^{\circ}$ DE JULHO DE 2015. Disponível em:

http://portal.mec.gov.br/docman/agosto-2017-pdf/70431-res-cne-cp-002-03072015-pdf/file.

Acesso em: 22 maio 2020. 
CARVAlHO, Anna M. Pessoa de.; GIL-PÉREZ, Daniel. Formação de Professores de Ciências. São Paulo: Cortez, 1995.

COELHO, Juliana Cardoso. A Chuva Ácida na Perspectiva de Tema Social:

Um Estudo com Professores de Química em Criciúma (SC). 2005. Dissertação (Mestrado em Educação Científica e Tecnológica). Curso de Pós-Graduação em Educação Científica e Tecnológica, Universidade Federal de Santa Catarina, Florianópolis, 2005. Disponível em: http://repositorio.ufsc.br/handle/123456789/101912. Acesso em: 29 abr. 2020.

CORTEZ, Jucelino. A Abordagem CTS no Contexto da Formação e da Atuação Dos Professores da Área de Ciências da Natureza. 2018. Tese (Doutorado em Educação em Ciências). Curso de Pós-Graduação em Educação em Ciências: Química da Vida e Saúde, Universidade Federal do Rio Grande do Sul, Porto Alegre, 2018. Disponível em: https://lume.ufrgs.br/handle/10183/180187. Acesso em: 29 abr. 2020.

CHASSOT, Attico. Alfabetização científica: uma possibilidade para a inclusão social. Revista Brasileira de Educação, v. 22. p. 89-100. 2003. Disponível em: https://www.scielo.br/pdf/rbedu/n22/n22a09.pdf. Acesso em: 10 mar. 2020.

FEISTEL, Roseli Adriana Blümke. Contribuições da Perspectiva Freireana de Educação para a Interdisciplinaridade na Formação Inicial de Professores de Ciências. 2012. Tese (Doutorado em Educação Científica e Tecnológica). Curso de Pós-Graduação em Educação Científica, Universidade Federal de Santa Catarina, Florianópolis, 2012. Disponível em: https://repositorio.ufsc.br/xmlui/handle/123456789/130870. Acesso em: 8 jun. 2020.

FERRÃO, Luciana Vigil; AULER, Décio. Os estudantes do arquivo morto. Revista Educação, Santa Maria, v. 37, n. 1, p. 1-14, 2012. Disponível em: https://periodicos.ufsm.br/reveducacao/article/view/3158/2716. Acesso em: 23 jun. 2020.

FERNANDES, Roseane Freitas. Educação CTS e Interdisciplinaridade: Perspectivas para Professores do Ensino Médio. 2016. Dissertação (Mestrado e Ensino de Ciências). Curso de Pós-Graduação em Ensino de Ciências, Universidade de Brasília, Brasília, 2016. Disponível em: http://repositorio.unb.br/handle/10482/22052. Acesso em: 29 abr. 2020.

FONSECA, Eril Medeiros. Abordagem de Temas no Ensino de Ciências: Reflexões para Processos Formativos de Professores. 2019. Dissertação (Mestrado Acadêmico em Ensino). Curso de Pós-Graduação em Ensino da Universidade Federal do Pampa, Bagé, 2019.

Disponível em: http://dspace.unipampa.edu.br:8080/jspui/handle/riu/4593. Acesso em: 29 abr. 2020.

HALMENSCHLAGER, Karine Raquiel; DELIZOICOV, Demétrio. Abordagem Temática no Ensino de Ciências: Caracterização de Propostas Destinadas ao Ensino Médio.

ALEXANDRIA: R. Educ. Ci. Tec., Florianópolis, v. 10, n. 2, p. 305-330, nov. 2017. Disponível em:

https://periodicos.ufsc.br/index.php/alexandria/article/view/1982-5153.2017v10n2p305. Acesso em: 10 maio 2021.

HORA, Bruna Lorena Valentim. Ensino de Ecologia sob a perspectiva CTS e investigativa: um caminho para o letramento científico. 2017. Dissertação (Mestrado em Ensino de Ciências 
e Matemática) Curso de Pós-Graduação em Ensino de Ciências e Matemática, Universidade Federal do Rio Grande do Norte, Natal. 2017. Disponível em:

https://repositorio.ufrn.br/jspui/handle/123456789/24421. Acesso em: 29 abr. 2020.

LÜDKE, Menga; ANDRE, Marli E. D. A. Pesquisa em educação: abordagens qualitativas. 2. ed. Rio de Janeiro: E. P. U., 2013.

MORAES, Roque; GALIAZZI, Maria do Carmo. Análise Textual Discursiva. 3. ed. Ijuí: Unijuí, 2016.

\section{MÜNCHEN, Sinara. A Inserção da Perspectiva Ciência-Tecnologia-Sociedade na}

Formação Inicial de Professores de Química: O Movimento Ciência-Tecnologia-Sociedade e sua Inserção no Contexto Educacional. 2016. Tese (Doutorado em Educação em Ciências). Curso de Pós-Graduação em Educação em Ciências: Química da Vida e Saúde, da Universidade Federal de Santa Maria, Santa Maria, 2016. Disponível em:

http://repositorio.ufsm.br/handle/1/3557. Acesso em: 20 mar. 2020.

NÓVOA, António. Formação de professores e profissão docente. In: NÓVOA, A. (org.). Os professores e a sua formação. Lisboa: Dom Quixote, 1995.

OLIVEIRA, Rosangela Rodrigues de. A História das Ciências no Ensino de Química: Implicações para uma abordagem CTS na formação continuada de professores. 2016. Dissertação. (Mestrado em Ensino e História das Ciências e Matemática). Curso de Pós-Graduação em Ensino, História e Filosofia das Ciências e Matemática, da Universidade Federal do ABC, Santo André, 2016. Disponível em:

http://biblioteca.ufabc.edu.br/index.php?codigo_sophia=105997. Acesso em: 29 abr. 2020.

PENHA, Pedro Xavier da; MACIEL, Maria Delourdes. Mapeamento do Enfoque CTS e o Saberes Docentes na Formação de Professores de Ciências. REnCiMa, v.10, n.3, 2019. Disponível em:

http://revistapos.cruzeirodosul.edu.br/index.php/rencima/article/viewFile/2134/1135. Acesso em: 29 abr. 2020.

RADETZKE, Franciele Siqueira; GÜLLICH, Roque Ismael da Costa. As pesquisas sobre a docência no ensino superior em contexto brasileiro. Revista Internacional de Educação Superior, v. 6, p. 1-25, 2020. Disponível em:

https://periodicos.sbu.unicamp.br/ojs/index.php/riesup/article/view/8655876. Acesso em: 27 abr. 2020.

RODRÍGUEZ, Andrei Steveen Moreno. Enfoque Ciência, Tecnologia E Sociedade (CTS): Contribuições para a Profissionalização Docente. 2018. Tese (Doutorado em Educação em Ciências). Curso de Pós-Graduação em Educação em Ciências: Química da Vida e Saúde, Universidade Federal do Rio Grande do Sul, Porto Alegre, 2018. Disponível em: http:/hdl.handle.net/10183/180977. Acesso em: 29 abr. 2020.

SANTOS, Wildson Luiz Pereira dos; AULER, Décio. CTS e a educação científica: desafios, tendências e resultados de pesquisas. Brasília: Editora Universidade de Brasília, 2011. 
SANTOS Wildson Luiz Pereira dos; MORTIMER, Eduardo Fleury. Uma análise de pressupostos teóricos da abordagem C-T-S (Ciência - Tecnologia - Sociedade) no contexto da educação brasileira. Ensaio Pesquisa em Educação em Ciências, v. 02, n. 02, p. 01-23, 2002. Disponível em: http://www.portal.fae.ufmg.br/seer/index.php/ensaio/article/view/21/52. Acesso em: 30 abr. 2020.

SANTOS, Wildson Luiz Pereira dos; SCHNETZLER, Roseli Pacheco. Educação em química: compromisso com a cidadania. Ijuí: Editora Unijuí, 2010.

SILVA, Karolina Martins Almeida. Abordagem CTS no Ensino Médio: Um Estudo de Caso da Prática Pedagógica de Professores de Biologia. 2010. Dissertação (Mestrado em Educação em Ciências e Matemática). Curso de Pós-Graduação em Educação em Ciências e Matemática, Universidade Federal de Goiás, Goiânia, 2020. Disponível em: http://repositorio.bc.ufg.br/tede/handle/tde/401. Acesso em: 29 abr. 2020.

SILVA, Maria José Aguiar dos Reis. Conceitos de Ciências para Educação do Campo a partir do Tema Agriculturas. 2014. Dissertação (Mestrado em Ensino de Ciências). Curso de Pós-Graduação em Ensino de Ciências, Universidade de Brasília, Brasília, 2014. Disponível em: http://repositorio.unb.br/handle/10482/18249. Acesso em 29 abr. 2020.

STRIEDER, Roseline Beatriz; KAWAMURA, Maria Regina Dubeux. Educação CTS: Parâmetros e Propósitos Brasileiros. Alexandria: Revista de Educação em Ciências e Tecnologia, v. 10, n. 1, p. 27-56, 2017. Disponível em:

https://periodicos.ufsc.br/index.php/alexandria/article/view/1982-5153.2017v10n1p27/34216. Acesso em 30 ago. 2020.

VIGOTSKI, Lev Semenovich. Pensamento e Linguagem. 4.ed. Rio de Janeiro: Martins Fontes, 2011.

ZABALA, Antoni. A prática educativa: como ensinar. Porto Alegre: ARTMED, 1998.

Recebido em setembro de 2020.

Aprovado em maio de 2021. 